\title{
Analysis on the Operating Cost of Chinese Herbal Medicine Enterprises from the Perspective of Supply Chain
}

\author{
Songwen Ye \\ Business School of Yulin Normal University, Yulin City, Guangxi \\ Province, 537000, China
}

\begin{abstract}
Supply chain management can effectively integrate enterprise resources, improve enterprise efficiency,so it is a key strategic factor to realize the long-term development goal of the enterprise. Based on the author's learning and practical experience, this paper first analyzed the characteristics of the operation and management of traditional Chinese medicine planting enterprises under supply chain management,then studied the basic status of Chinese herbal medicine, finally put forward the cost analysis model. The research results of this paper are of great significance to the establishment of a more efficient and orderly circulation system.

Keywords: Supply chain; Chinese herbal medicine; Enterprise management; Cost analysis

\section{Introduction}

In the process of promoting the modernization of traditional Chinese medicine, the industrialization of traditional Chinese medicine has promote the popularization of traditional Chinese Medicine, but for a long time, The dispersion mode of Chinese herbal medicine planting with "farmers" as the main body has restricted the expansion of the scale, while the quality of medicinal materials can not be guaranteed[1]. At present, the country vigorously promote the standardization of planting GAP, and the "company + farmer" planting mode has undoubtedly changed the standardization of Chinese herbal medicine planting.
\end{abstract}


After signing an agreement with the farmers, enterprises guide farmers to grow herbs and then acquire these herbs. After the acquisition of quality inspection and preliminary screening, the companies will pack and store these herbs and finally choose the right transportation to the market.

\title{
2 Characteristics of Operation and Management of Traditional Chinese Medicine Planting Enterprises under Supply Chain Management
}

\author{
2.1 The model of "company + farmer" is helpful to protect farmers' \\ enthusiasm
}

After the selecting the species,enterprises let local farmers plant. In this process, enterprises provide them with seeds and sign agreements with them,give them planting technical guidance. In this way, it can avoid the uneven quality of the medicinal materials due to the subjective operation and technical differences. At the same time, due to the agreement signed with farmers, enterprises purchase drugs at an agreed price, which can avoid to dampen the enthusiasm of farmers caused by price fluctuation.In addition, the lower costs brought by large-scale planting will make the product more competitive in the market[2].

\subsection{The company's quality screening is helpful to improve the quality of medicinal materials}

Despite the technical guidance to farmers, there will still be differences in grades.Under the guidance of technical regulations, the preliminary screening of raw materials, the classification of raw materials, plant classification.Use hightech instruments to the determine the pesticide residues, heavy metals and other indicators. Part of the medicinal materials can also be processed to be pieces. The medicinal materials after screening and evaluation not only can guarantee the quality, but also increase the added value of the product, so it can meet the international market standardization, quality requirements, and strengthen the international competitiveness of Chinese herbal medicines[3]. At the same time, it is helpful to change the traditional situation of the appearance and quality of Chinese herbal medicines.

\subsection{Standardized packaging, storage and transportation is conducive to improve product competitiveness and circulation efficiency}

Under the standardization technical regulations, the enterprise carries on the packing to the screening classification medicinal material, which can change the traditional packaging using sacks, rope to package the medicine, so it is helpful to ensure the cleanness and hygiene of medicinal materials, and can increase the added value of products. Standardized storage conditions can ensure the preservation of the most appropriate temperature and humidity, which is 
conducive to long-term preservation, reduce the improper storage due to the deterioration of raw materials and the loss of effective components. In addition, the choice of appropriate transport tools to the market throughout the country can also make the circulation more efficient and orderly.

\section{Basic Situation of Chinese Herbal Medicine Planting}

\subsection{Development mode is single}

The mode of "farmer + market" is the traditional mode of production and circulation of Chinese herbal medicines. As the Chinese herbal medicine planting has always taken the model of "farmer + market", there are a large number of farmers, widely distributed, and the number of drugs in the hands of each farmer is less, the quality is uneven[4]. This model has played a key role in the development of traditional Chinese medicine industry in the traditional drug trade. However, with the traditional Chinese medicine industry developing towards modernization and industrialization, this model has been unable to keep up with the pace of the times, and the most important is the quality of Chinese herbal medicines can not be guaranteed.

\subsection{Price fluctuations is difficult to control}

Chinese herbal medicine is a special kind of agricultural products, but with the continued growth of the scale of traditional Chinese medicine industry, its profits have not increased.The situation of increasing production without increasing income is becoming more and more serious, and the price volatility is one of the main reasons. Because of the market supply and demand information asymmetry, farmers can not grasp the demand information, so a large number of herbal medicine may decay in the market,which greatly dampened the enthusiasm of farmers. At the same time, it also may lead to insufficient supply of raw materials, rising prices, affecting the production and export of medicinal materials[5].

\subsection{A Distribution of traditional Chinese medicine market}

Different with cotton, soybeans and other agricultural products, after the acquisition from farmers, Chinese herbal medicine mainly through the completion of the professional trading market. At present, the country relies on the production of traditional Chinese medicine and the traditional distribution center has formed 17 major market, but such a collection of transactions often cycle long. The goods have been transported many times, so the cost of storage and transportation management has also increased substantially. This caused the operator inventory and capital turnover rate is very slow, so the operator's cost of drug prices continue to rise. If we based on the GAP standardized planting to introduce the supply chain management theory, and try to set up a set of management system in line with the characteristics of traditional Chinese 
Medicine, China's current situation of chaotic distribution of herbal medicines will be changed.

\section{Cost analysis model of traditional Chinese medicine enterprises}

\section{1 inventory maintenance costs}

Inventory maintenance cost is one of the core costs in the supply chain, and it can dramatically increase the profit of the whole supply chain as long as it drops a few points. In the calculation of inventory costs, it is often necessary to consider warehousing, liquidity needs, rent, wear, insurance, tax and other aspects. For the cultivation of Chinese herbal medicine enterprises, the size of the acquisition of raw materials is essential to their interests[6]. Determining the total annual purchase of raw materials is based on the determining of the size of the agreement signed with farmers and processing and transportation capacity arrangements. In the case that total demand for raw materials is determined in advance, when a single purchase quantity of a certain medicinal herb is less, the acquisition will increase and the cost will increase, but at this point the company has a lower average inventory level, resulting in lower inventory holding costs. On the contrary, if the volume of enterprise acquisition is large, the acquisition cost will be reduced and the inventory cost will be increased. If we can find an optimal batch that can minimize the ordering cost and inventory cost and establish a model based on market demand, it will be good for the cost analysis and accounting of Chinese herbal medicine planting enterprises.

(1) Determine the amount of purchase: $\mathrm{R}=\mathrm{d} \times \mathrm{L}+\mathrm{SS}$. In this formula, $\mathrm{R}$ - the amount of purchase; d - average daily demand; L - advance time; SS - safety stock. When determining whether or not to increase the amount of acquisition, we consider the amount of re-acquisition to compare whether the additional acquisition should be conducted. If the existing inventory plus the quantity of the ordered inventory is lower than the determined reorder quantity, the additional amount will be added. If $\mathrm{I}+\mathrm{Q}_{0} \leq \mathrm{R}$, the amount of purchase is $\mathrm{Q}$. In this formula, I - existing inventory, $\mathrm{Q}_{0}$ - number of ordered. At the time of the inventory level is $I^{\prime}=Q / 2+S S$. In this formula, $I^{\prime}$ is the average inventory.

(2) Calculate the average inventory cost. Assume that the demand for Chinese herbal medicine is $\mathrm{D}$, according to the above formula, the average inventory is multiplied by the storage cost of the medicinal material, and the average inventory maintenance cost is obtained. $\mathrm{Ch}=\mathrm{I}^{\prime} \mathrm{C}_{\mathrm{i}}\left(\mathrm{P}+\mathrm{C}_{0} / \mathrm{D}\right)$. In this formula, $\mathrm{C}_{\mathrm{h}}$ is the average inventory maintenance $\cos t ; \mathrm{C}_{\mathrm{i}}$ is the percentage of per unit cost of storage per unit; D - year demand; $\mathrm{P}$ - unit price of the acquisition of medicinal herbs; $\mathrm{C}_{0}$-annual purchase cost. 


\subsection{Transportation costs}

Transportation is one of the most intuitive elements in logistics operation, and the main function of transportation is the movement of products in the value chain[7]. Since transportation is the use of time resources, financial resources and environmental resources, then only when it does improve the value of the product, the product movement is meaningful and reasonable. Transportation costs are usually affected by distance, load, handling and market factors. The distance and the load weight are the most important factors, and their relationship with the transport costs, as shown in Figure 1 and Figure 2.

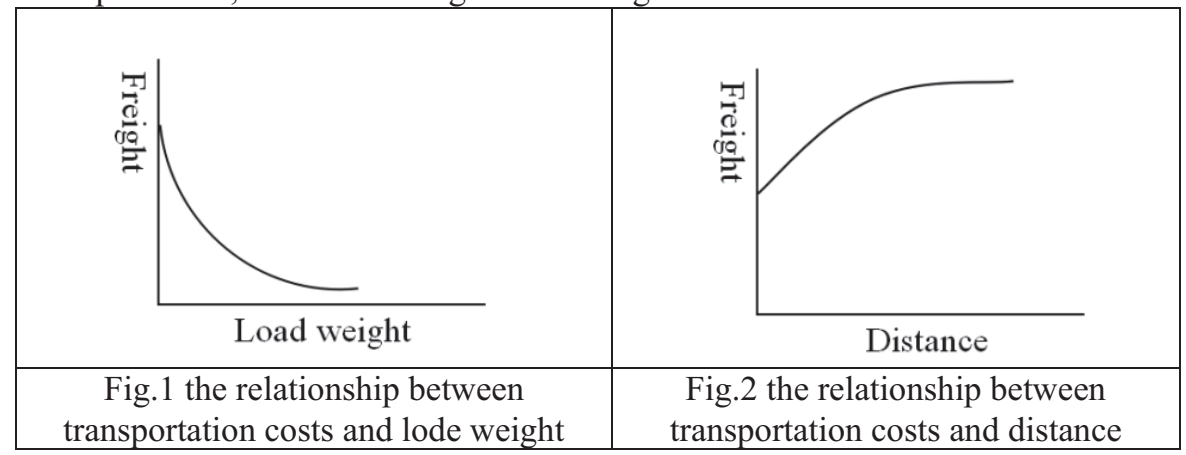

Assuming a total of $\mathrm{N}$ times transport per a year, the transportation costs can be expressed as follows:

$$
\begin{aligned}
& C \mathrm{t}=\left[\sum\left(C_{\mathrm{f}}+C_{V} Q_{\mathrm{i}}\right)\right] / T Q \\
& =\left(\mathrm{n} C_{\mathrm{f}}+C_{\mathrm{v}} T Q\right) / T Q \\
& =\mathrm{n} C_{\mathrm{f}} / T Q+C_{\mathrm{v}} \\
& =C_{\mathrm{f}} / Q^{\prime}+C_{V}
\end{aligned}
$$

In this formula, $\mathrm{Cv}$ - Variable cost per unit of medicinal herbs; TQ - Total annual transport volume; Q' - Average load of N times; Qi - carrying capacity of the $\mathrm{i}$ times $(\mathrm{i}=1,2,3 \ldots)$; Total annual transport volume $\mathrm{TQ}=\sum \mathrm{Qi}$; Annual total transportation cost $\mathrm{Ct}=\mathrm{C}_{\mathrm{t}} \mathrm{TQ}=\mathrm{nC}_{\mathrm{f}}+\mathrm{C}_{\mathrm{v}} \mathrm{TQ}$. As can be seen, the cost is only related to $\mathrm{N}$ and $\mathrm{Q}$, and it has nothing to do with the type of product. If all the products are used to share the fixed cost, the scale economy will be produced.

\section{Conclusion}

As the most basic link in the chain of traditional Chinese medicine, the number of farmers is extremely large, and is easy to be affected by short-term behavior. Their compliance with the agreement is lower, which may increase the difficulty of strategic partnership management, so the logistics work is complicated and cumbersome. Compared with the manufacturing enterprises, the cultivation of 
traditional Chinese medicine is often faced with natural risk, policy risk, market risk, therefore, using the supply chain theory to guide the cultivation of Chinese medicinal materials has a great significance for the realization of the modernization goal of traditional Chinese Medicine.

\section{References}

[1] $\mathrm{Gu}$ Yu.Analysis and optimization of logistics cost. China's Circulation Economy,11, pp.16-19, 2005.

[2] Wu Jinglian. The implementation of supply chain management to improve the competitiveness of China's circulation industry. China's Circulation Economy, 10, pp.6-8, 2003.

[3] Kong Min. Research on internal control system based on supply chain. Cooperative Economy and Technology,02, pp.30-33, 2009.

[4] Xiao Peichi. Strengthening the supply chain management to enhance the core competence of the enterprise. Journal of Henan College of Finance and Taxation, 03, pp.40-42, 2009.

[5] Chen Gang. Optimization of supply chain management in coal enterprises. Coal Economy Research, 06, pp.62-64, 2010.

[6] Hu Li, Zhang Wensheng, Zhang Bin. The development pattern of Chinese herbal medicine planting enterprises under the supply chain management system. Chinese Journal of Traditional Chinese Medicine, 08, pp.4-6, 2007.

[7] Yang Haoxiong, Wei Bin. Game Analysis on quality safety control of traditional Chinese medicine pieces from the perspective of supply chain. Chinese Journal of Traditional Chinese Medicine Information, 07, pp.11-16, 2016. 